\title{
Urban aesthetic and urban landscape design guides: A case study of Bartın- Turkey
}

\section{Authors Info}

\section{D. Çelik ${ }^{1 *}$ and S. Açiksöz ${ }^{2}$} ${ }^{1}$ Programme of Landscape and Ornamental Plants, Vocational High School, Bartın University, Bartın, 74100, Turkey

${ }^{2}$ Department of Landscape Architecture, Faculty of Forestry, Bartın University, Bartın, 74100, Turkey

*Corresponding Author Email : dcelik@bartin.edu.tr

Key words

Bartın-Turkey,

Landscape design,

Townscape,

Urban aesthetic

\section{Publication Info}

Paper received : 30.07 .2016

Revised received : 20.06.2017

Accepted : 26.06.2017

\section{Abstract}

Aim: Natural, cultural, economic and structural features affect the urban aesthetics. With globalization, cities have entered into a process of change and transformation, but often failing to preserve their identity and aesthetics. The aim of the study was to find an answer to the following questions: How should be the urban design guides, who will pave way for new studies on the formation, observation and maintenance of sustainability in urban aesthetic? What is the relationship between aesthetic and urban design guides?

Methodology: The study was carried out in Kanlırmak District in Bartın-Turkey in four stages: data collection, analysis, evaluation, results and suggestions.

Results: In this context, design guides for open and green areas, street texture, building frontages, and urban furniture in Kanliirmak District had improved. The street silhouette of the selected area was prepared in accordance with the Urban Design Guides; its present structural and planting state was identified.

Interpretation: There being no urban design guides peculiar to Bartın, partial solutions were found for the plans and projects in the protection studies. Results are believed to be efficient in forming Bartin urban aesthetic and to be useful in future for other cities that naturally and socio-culturally resemble Bartin to the city from the aspect of urban aesthetic.

*The abstract was published in 2011 ECLAS Conference on Ethic/Aesthetics, $07-10$ Sept. Sheffield-UK, but the data presented here have been improved.
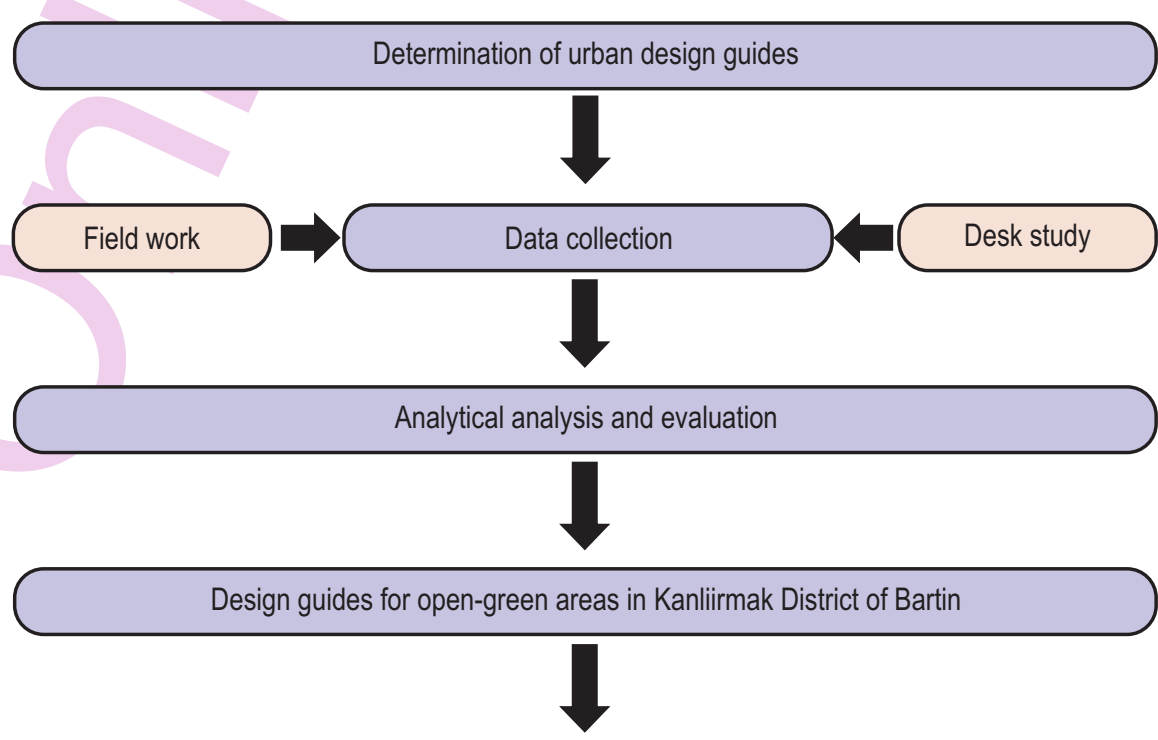

Street silhouette of Kanliirmak street 


\section{Introduction}

The origins of aesthetics date back to Ancient Times. The emotions that shape the physical relations that human beings establish with environment and the value system when these emotions turn into perceptions form the environment aesthetics (Ziss, 2011; Erzen, 2007). The terms "beautiful" and "art" come to mind when the word "aesthetics" is mentioned and they cannot be considered separately. Aesthetics is stated as a general view, a perspective, a general appreciation or set of rules that materialize/will materialize in a unique way of design (Timuçin, 2008; Erzen, 2011). In landscape architecture, on the other hand, the relationships between environment and ecological aesthetics are very close and create an area of impact covering a wide range of topics.

All kinds of settlements disturb existing ecological balance, and change the physical shape of the area as well as the aesthetic data of the environment (Erzen, 2006). Therefore, greenery and structural environment should be designed in a way that it is sustainable not only in technical terms but also in aesthetical terms, which incorporates both natural beauty and symbolism (Pollock-Ellwand, 1994; Roeser, 2013). Giving an identity to the city with the landscaping done in accordance with city's unique characteristics, is important for improving existing urban structure (Topay and Gül, 2009). One of the properties affecting the city identity is rivers. Rivers are important components of urban ecosystem and infrastructure (Zhang and Wang, 2015).

The concept of aesthetic justice is the notion of equity planning within aesthetic dimension of planning. So, aesthetic justice requires relevant guidelines for the urban planning and design (Mattila, 2003). Kevin Lynch developed the conceptual framework of urban design in a multidimensional way. In his book "The Image of the City" Lynch claims that subjects form urban image with the help of five main urban elements. These are paths, edges, districts, nodes and landmarks (Lynch, 2010). In addition, the new concept of urbanization includes three main interrelated areas, viz., empirical performance, ideological and cultural issues, and aesthetic quality (Ellis, 2002). Besides, user demands, life style and culture should also be taken into consideration as landscape values in the renewal process of open green areas which is a part of the urban (Lee et al., 2014). It is important to consult the ideas of local people in a participative way especially in the process of sustainability/ protection of historical cities (Sotoudeh and Abdullah, 2013). Thus, physical design and aesthetic character have a significant impact on the development of the society (Deng, 2005). Urban aesthetic is not only a combination of individual beautiful elements. Urban aesthetic is related to creating a context and applying it to the whole public life. The main thing is to set the system and rules of combination (Keskinok, 2010).
Urban design guidelines have become an important ingredient for making urban design better associate with urban planning management (Hong and Tao, 2015). Design guides as well as laws and regulations support formation and sustainability of the urban aesthetic. Design guides are the most important tools of urban design projects. Guides include directions explaining standards, methods and techniques. Apart from the resolutions in the construction plan reports' planning notes, design guidelines include such details as third dimension architectural character, material and engineering (Özer and Söylemez, 2010). Urban design guidelines include planting design. Urban greening provide various benefits to cities. For example improving the quality of life, absorbing dust and noise, reducing $\mathrm{CO}_{2}$ emissions and pollution in the air, minimizing the wind speed, and decreasing the risk of erosion (Madan and Verma, 2015; Weina et al., 2015; Galenieks, 2017; Selitsaniotis and Nikolaou, 2009; Ely and Pitman, 2014). Urban design guidelines for Austin, Pittsburgh, Nottingham, Toronto and Downtown Corel Spring cities are summarized below.

In street design guides for Austin, humane character, density, sustainability, diversity, economic vitality, civic art, sense of time, unique characteristic, authenticity, safety, connection to outdoors make up the basic character (URL1, 2009). Guidelines for the city of Pittsburgh, state that buildings should not hinder main gateways in the city or most important sights in the center (URL2, 1998). The main part of Nottingham city center conserves historic perspective. Urban Design Guidelines for Nottingham are classified in seven sections: urban form, public realm, alleyways, massing, activity, sustainability and design; and strategies are developed for each section (URL3, 2009). Urban Design Guidelines for Toronto are used to enforce Official Plans and urban design aims via laws. Guides were helpful in turning policy and performance standards into criteria for approval to be considered by municipalities (URL4, 2013). For Downtown Coral Spring urban design guidelines were prepared and street types were defined. Landscape and street scape designs for each of the defined street type were suggested, and thus landscape design guidelines were formed (URL5, 2002).

The main objective of this study, carried out at the Kanlırmak Region in Bartın, was to form urban design guides which will pave the way for new studies on the formation, observation and maintenance of sustainability in urban aesthetic. Another objective of the study was to investigate the relationship between aesthetic and urban design guides in the area.

\section{Materials and Methods}

Kanlırmak District of Bartın city of Turkey was selected as the study area for this research. The region lies between the borders of Reconstruction Plan for Protection and first Degree Protected Area, in the transit area of Bartın stream and incorporates registered buildings (Fig. 1). Bartın city (32-33' East 


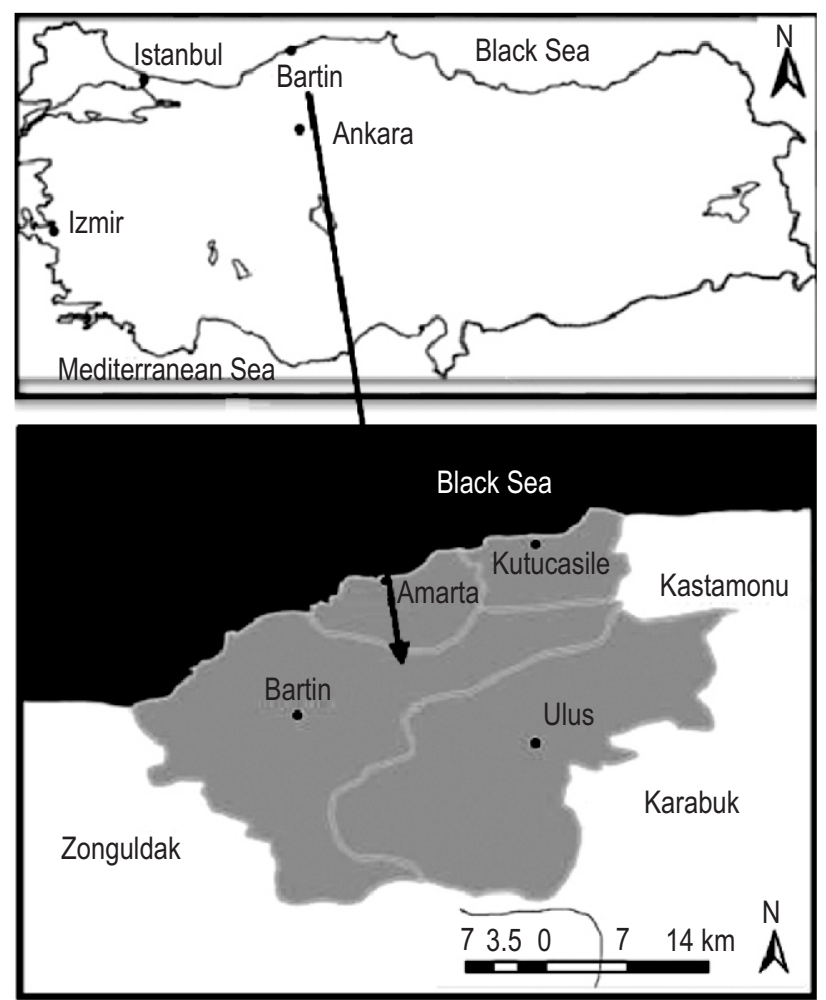

Fig. 1: Location of the Bartın in Turkey

longitude and $41^{\circ}-53^{\prime}$ North latitude) is located in the Western Black Sea region (Anonymous, 2008). 1/5000 scaled master plan and $1 / 1000$ scaled implementary development plan are used in the analysis studies of Bartın city.

Methodology of the study was determined after a review of earlier studies (URL1, URL2, URL3, URL4 and URL5). The study was carried out in four steps: data collection, analysis, evaluation, results and suggestions. The first step included collecting data on the issue and the area from literature. Next, the area of Bartın was analyzed using the $1 / 1000$ scaled implementary development plan. In the third step, all collected data were assessed and finally, design guidelines were developed for the open and green areas, street texture, building façades and urban furniture in Kanlırmak District.

\section{Results and Discussion}

Results on planning process of Bartın city : The first construction plan of Bartın city was prepared in 1957. Later, various construction plans were prepared in 1970, 1980-1983; present day revisions were made over existing construction plans for reasons such as population increase, and vehicle and pedestrian traffic growth (Anonymous, 2006). The tourist spots in Bartın city center and temporary settlement conditions were first determined in 1979. In 1981, Bartın stream was declared as a natural protected area and in 1985, the decision to register 231 buildings was taken (Aşcıoğlu, 2001). The first Reconstruction Plan for Protection was made in 1982. Currently, the new Reconstruction Plan for Protection, which came in force in 2003, was used (Anonymous, 2006).

Results of the Kanlırmak District: Bartın houses showcase the civil architecture of Ottoman Period and reflect the sense of aesthetics, lifestyle and culture of the past. Reflecting Art Nouveau and Baroque styles, Bartın houses are mostly two or three-flat houses inside a garden surrounded with a wooden fence called "Daraba" (Anonymous, 2007). In terms of façade organization, there is a symmetrical look in the houses. The roofs are covered with pantiles (Aşcıoğlu, 2001) (Fig. 2). The works of local authorities to protect the urban identity grew with the membership to Association of Historic Towns. The studies regarding protection are executed by Bartın Municipality Directorate of Planning and Settlement. Works such as street improvement, relievo and restoration of historical buildings that have been made and continue to be made protect and keep intact historical fabric. However, changes and transformations in historical fabric have caused emergence of visual pollution damaging urban aesthetics. The reasons behind these problems are socio-cultural change (migration, change in lifestyle, etc.), physical wear, political changes and financial restrictions. Destruction of civil architecture, one of the most important elements of urban identity, and spoilage of visual quality effected urban aesthetics seriously (Çelik and Açıksöz, 2008). Lynch (2010) stated that they formed urban image with five elements, viz., paths, edges, districts, nodes and landmarks. The working area is analyzed according to these parameters. When the
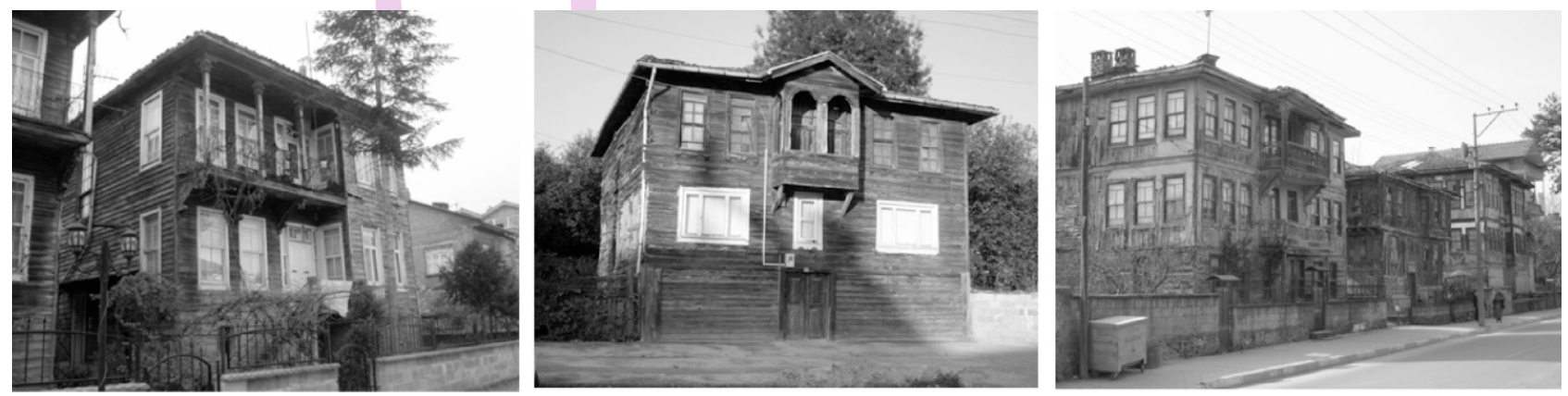

Fig. 2 : Traditional Bartın houses in the study area 


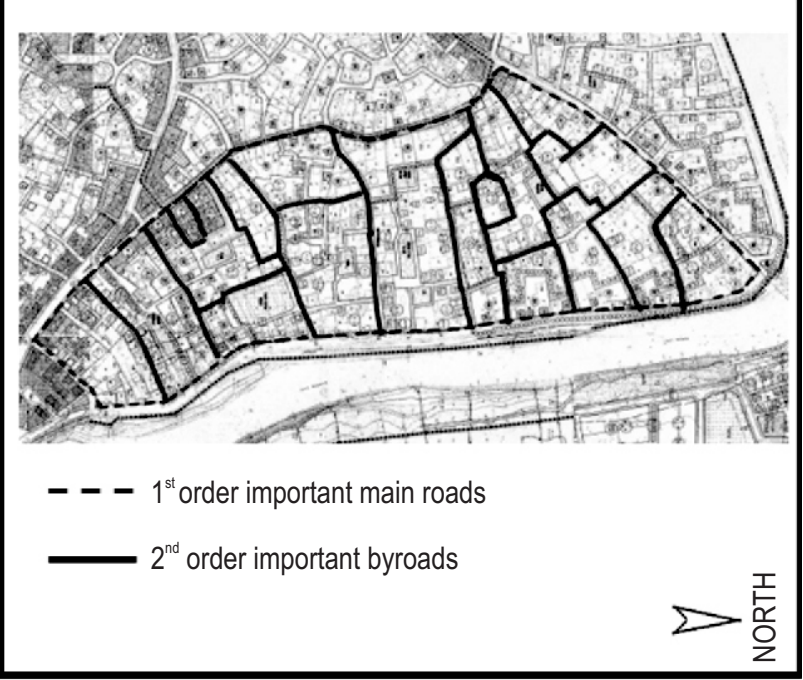

Fig. $3: 1^{\text {st }}$ order important main roads and $2^{\text {nd }}$ order important byroads of the study area

vehicle traffic is heavy on main roads, the vehicle traffic in the byroads decreases. There are blind streets in the area (Fig. 3).

When the factors effective in visual perception are considered, façades and garden walls are accepted as the vertical border of the streets. These borders separate two regions: the housing zone and housing + business zone. The surfaces of façades are wooden or concrete; the garden walls are of rubble stone, briquette and bricks (Fig. 4). Housing is dense in Kanlırmak Street while housing + business use is dense in the rest of main streets. It is, therefore, possible to separate the study into two districts (Fig. 5). Orduyeri Bridge, fire brigade, TEDAŞ Building, petrol station, Bus Station and Terminal Station are significant elements in the area. These elements are not physically high but are significant for their use. They help people in finding directions, and thus make it possible to describe specific urban elements as a base (Fig. 6).

Historical civil architecture samples are mostly located in Kanlırmak Street. People live in some of these buildings, rest of buildings are abandoned. Rubble stone is used in garden walls of these houses. Garden gates are two-winged and made of wood or metal. The main road is asphalted and has a pavement. The width of the main streets is $7 \mathrm{~m}$ while the width of by-streets ranges between 3-5 m. Mostly, there are no pavements in bystreets. Concrete paving blocks are used in the streets.

Briquette, brick and rubble stone are used in garden walls in by-streets. The barriers of garden walls are mostly solid black painted wrought iron. In one of the streets of the district (Ethnography Museum Street), a study was conducted in the scope of street improvement. Decorative road lighting was used in this street: granite cube stones, andesite, basalt and concrete cube stones were used on the ground. Briquette was used in garden walls while solid black painted wrought iron was used in wall barriers (Fig. 7).

Transportation arteries in the worksite are two-way. There is no plantation on the sides of road. Electricity pylons, energy transmission lines and satellite dishes cause visual pollution (Fig. 8). People grow plants in the gardens of their houses. The species of trees, shrubs and cultivated plants in the study area as follows: Hibiscus sp., Malus sp., Eriobotrya japonica, Cerasus avium, Kerria japonica, Passiflora incarnata, Ocimum basilicum, Liriodendron tulipifera, Picea exelsa, Abies sp., Daphne sp., Wisteria sinensis, Punica granatum, Fraxinus sp., Cedrus sp., Nerium oleander, Pinus sp., Ficus carica, Campsis radicans, Corylus avellana, Ailanthus altissima, Diospyros kaki, Lonicera caprifolium, Morus alba, Juglans regia, Prunus cerasifera, Acacia sp., Tilia sp., Laurocerasus officinalis, Syringa vulgaris, Cerasus vulgaris, Chaenomeles japonica and Hedera helix.

Species of ornamental plants and vegetables in home gardens are as follows: Dianthus sp., Hydrangea macrophylla, Ricinus communis, Vitis vinifera, Zea mays, Phaseolus vulgaris, Lycopersicon esculentum, Capsicum annuum, Solanum melongena, Cucurbita pepo, Lactuca sativa, Aucuba japonica, Picea pungens. Euonymus japonica, Berberis thunbergii, Pyracantha coccinea, Thuja sp. and Rosa sp.

Based on the data collected through review of literature and analyses of the area, an urban landscape design guide is suggested for existing historical buildings around Kanlırmak Area, for new buildings to be constructed, façades of buildings,
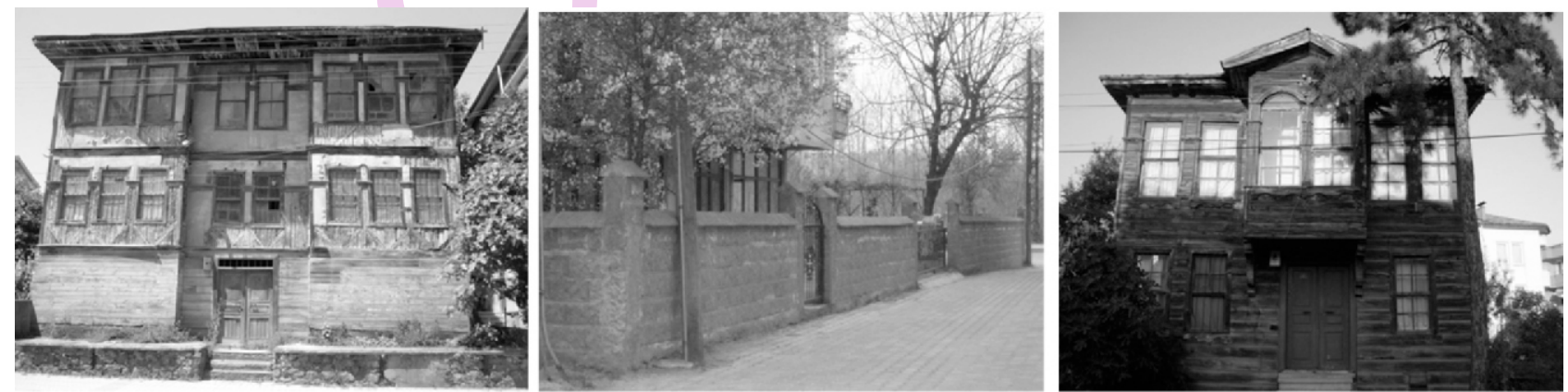

Fig. 4 : Border/ edge of the streets in the study area 


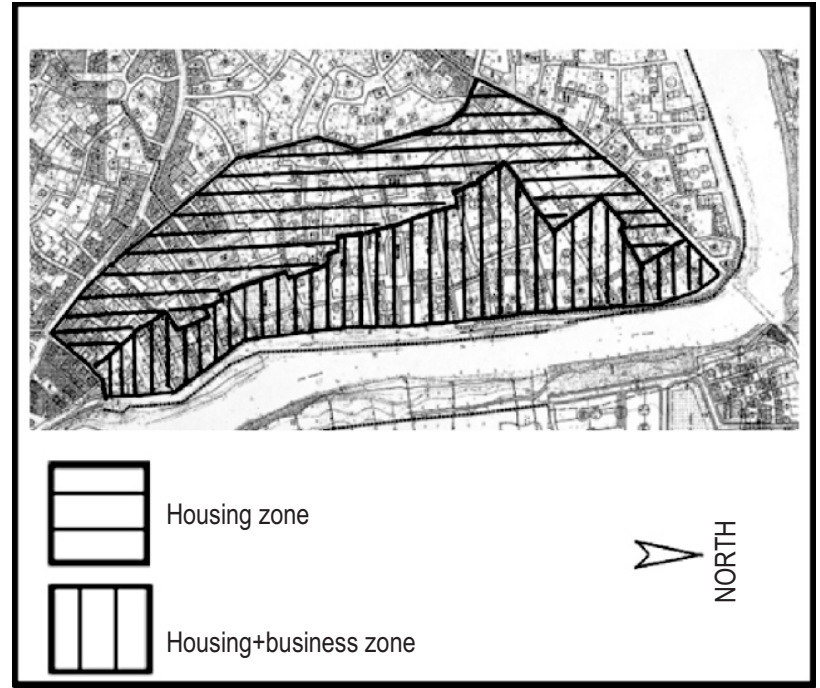

Fig. 5: Housing zone and housing+ business zone in the study area

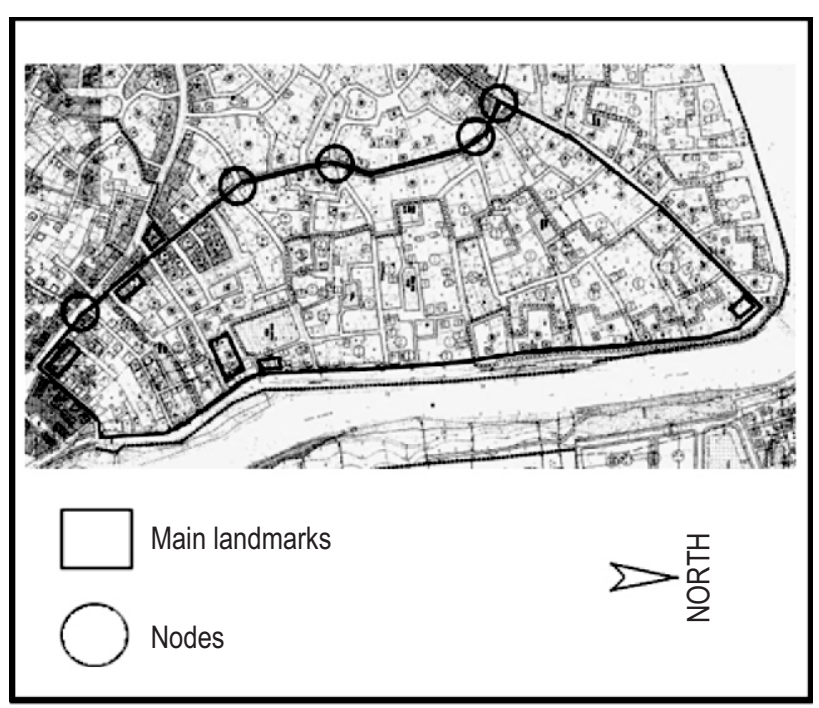

Fig. 6: Main landmarks and nodes in the study area
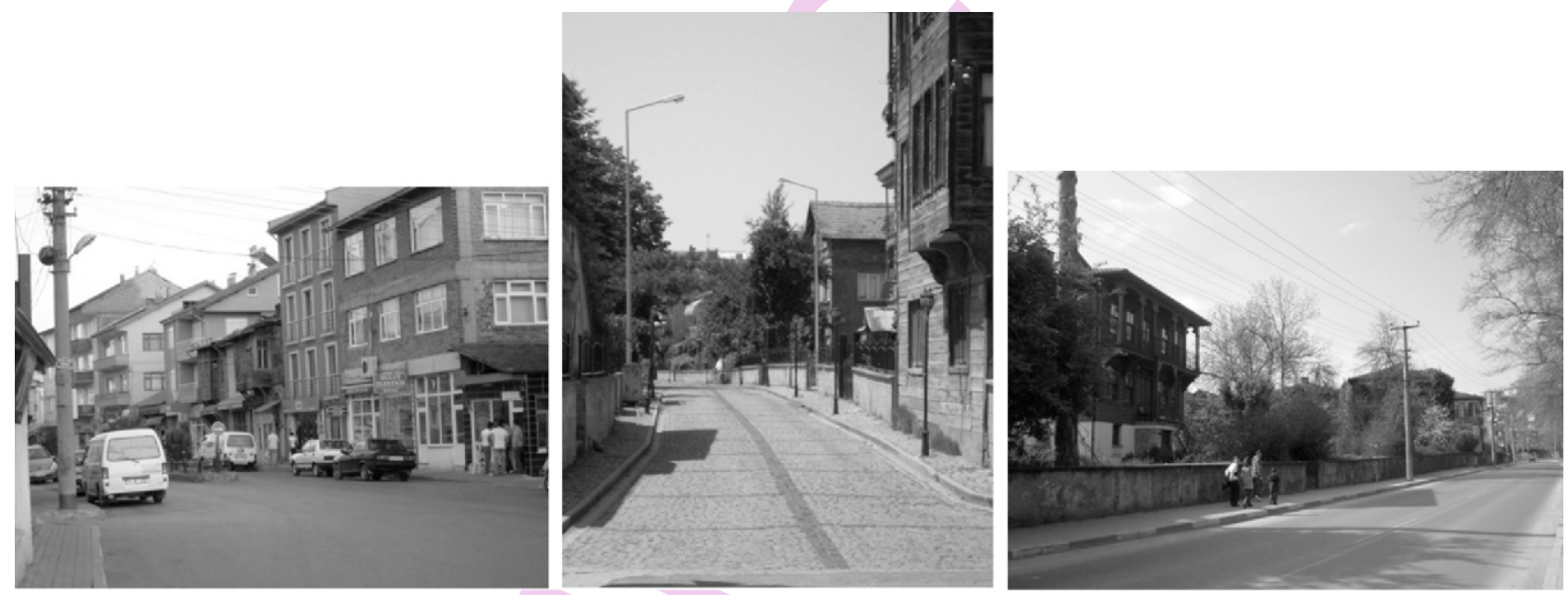

Fig. 7: Main roads and side roads in the study area
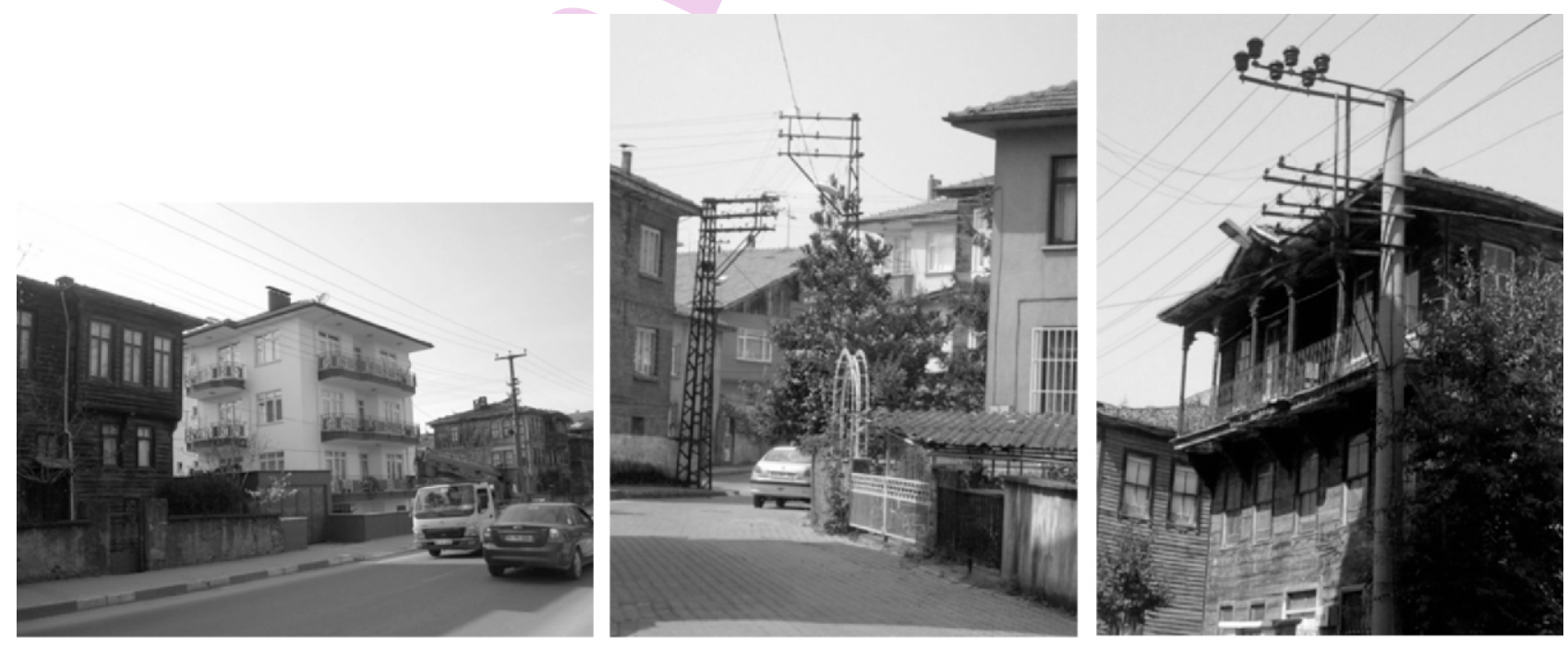

Fig. 8: Lamp posts that cause visual pollution 


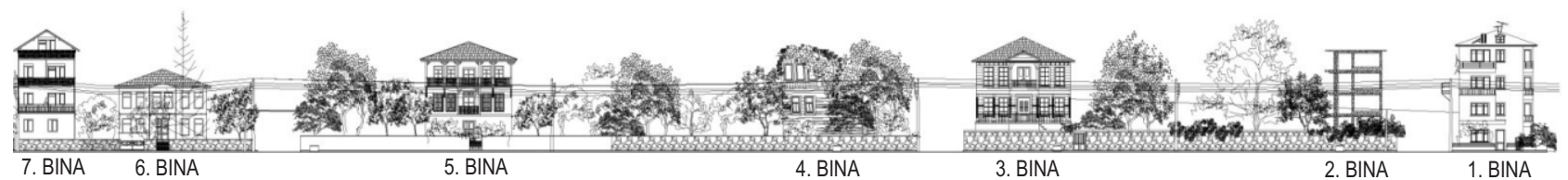

Fig. 9 : Street silhouette of Kanlırmak Street

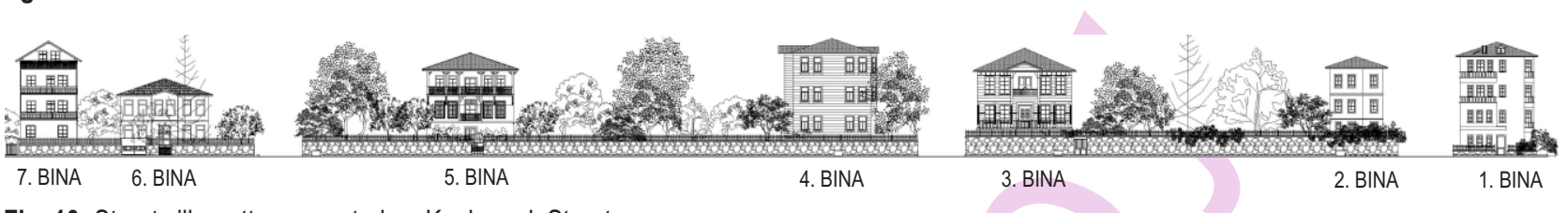

Fig. 10: Street silhouette suggested on Kanlırmak Street
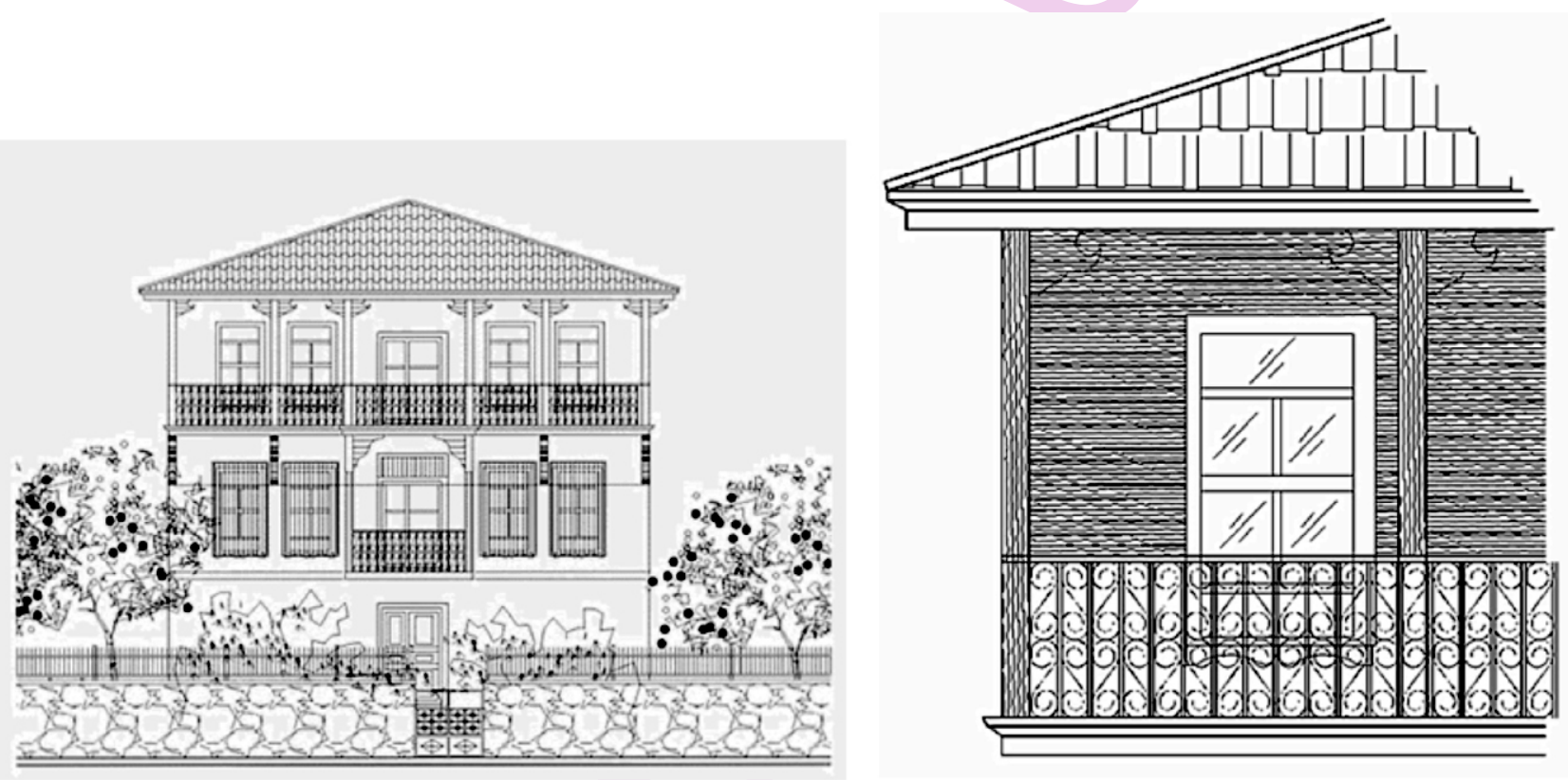

Fig. 11: Traditional civil architecture

urban community facilities and for open and green spaces.

In the suggested design guideline, the basic requirements of Bartın-Urban Protected Area, the plan conditions of Breakthrough Transition Area Conservation Zoning Plan of the Streets to be protected are based on Anonymous (2003).

In addition, design guides of Austin, Pittsburgh, Nottingham, Toronto and Downtown Coral Spring cities are used to indicate the similarities and differences of the suggested urban design guide.

Although there are historical buildings in Bartın city, the city does not have an intense historical fabric. Therefore, a large part of the city center is different from Nottingham city which has a historical character. However, the design guide suggested for the city is similar to the design guide of Nottingham city. This similarity arises in the necessity for adaptation of new buildings to architecture of historical buildings, gradation of roads, creating cycling paths and in improving and increasing open and green spaces. In addition, all historical buildings should be protected, maintained and repaired.

In Pittsburgh Urban Design Guide, it is suggested that the new buildings, the bridges over the streets and other buildings should be built in a way that will not obscure the main view in the city center or the main passages. In the Urban Design Guide in the study area, there are similar suggestions. It is stated that it is necessary that the new buildings to be constructed should not prevent the main view. There are also suggestions on the architectural design and materials to be used. It is recommended that new buildings should bear traditional architectural empty-full rate features on their façades so that these ensure compliance with historical fabric. The façades should be veneered or plastered. Windows are to be in the size of $1 / 2$; wood or wood-like materials should be used in windows, doors and jambs. Pantile 

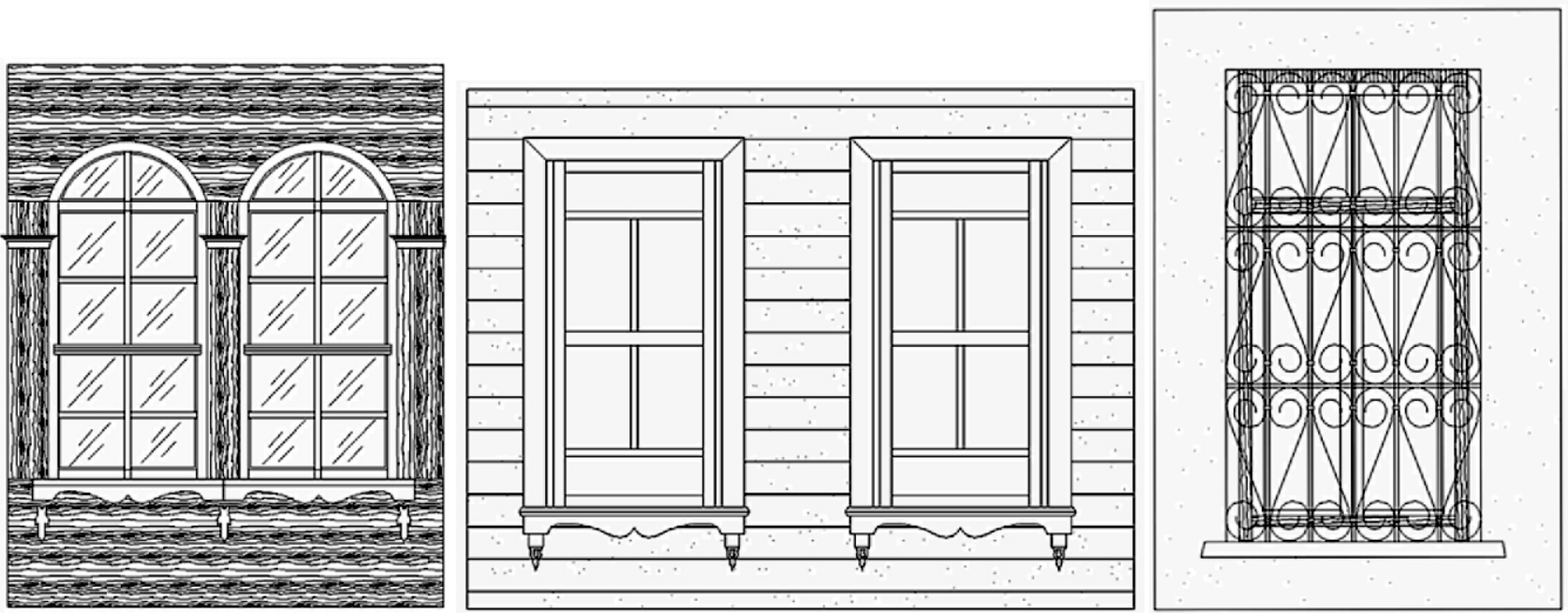

Fig. 12: Window detail in a traditional civil architecture

should be used on the roofs, garden walls and doors should reflect the traditional architectural features, and rubble stone or natural stone, which give this appearance, should be used in the walls.

Urban Street Design Guide prepared to improve Austin Street view proposes that community facilities should be in harmony with each other and with the environment they exist in. The public utility lines should be placed underground. Suggestions in the Urban Design Guide for the study area are similar to those in Austin Urban Street Design Guide. For example, the urban community facilities (such as dustbins, benches, lighting elements) should be in harmony with historical fabric in terms of material, colour, fabric and style. Direction plates should be placed in appropriate locations for easy view. Materials used in sun shields should be in harmony with the colours in the historical fabric (like white and beige). It is necessary that the wrought iron works should be black and dull in colour, that the surfaces of billboards should not be more than $0.50 \mathrm{sqm}$, the materials chosen should be enduring, easy to apply and economic. It is suggested that the electricity and telephone lines should be put under ground and the dish antennas should be connected to a central system. Different from Austin, there are fountains on Bartın streets which are like a continuation of traditional life. These existing fountains should be protected and if they are not in use, they should be put into use and environmental planning should be made.

The covering materials should be chosen by considering the climatic conditions of the historical city. Materials which will make it easy to walk on the ground should be chosen. It is suggested that cobblestone pavement or granite cube stones should be used in pedestrian ways. Using concrete paving blocks is not suggested.
The width of the streets in Austin and the study area are different. Since the streets in the study area are narrow, street tree planting could not be done. In Austin Urban Street Design Guide, there are such suggestions as: the trees should be located through the passages of pedestrians; while designing the organization of the trees on the street, their relationship with other buildings and street materials should be taken into account; trees that could adapt to the hard conditions of intense urban environment should be preferred. In the study area, on the other hand, there are suggestions about plant regulations on open and green spaces instead of the streets. Within this scope, species that are convenient for the climate and soil features of Bartın city should be preferred. Existing plants should be protected and such maintenance works as irrigation, pruning, fertilization and pest and disease control should continue. The plant materials should be in harmony with the historical fabric in terms of shape, colour and fabric. Plant materials that will not damage historical buildings and the foundation of the buildings should be chosen.

Similar to Nottingham and Austin urban streets, pedestrian-scale installation and energy-efficient lighting are suggested in the study area.

In urban design guide for Downtown Coral Spring there are such standards as standards for use, density and height. There are such definitions as the closeness to present residential use, relationship of height and massing to present and proposed street widths and close by open spaces, and the up-to-date and desired dispersion of land uses across and neighboring on the district. Similarly, there is a road separation in the study area as well. Other suggestions include that there should be pavements on main roads, the new constructed buildings should not be higher than the historical buildings, and that empty-full ratio on the façades should be in harmony with the historical structure. 

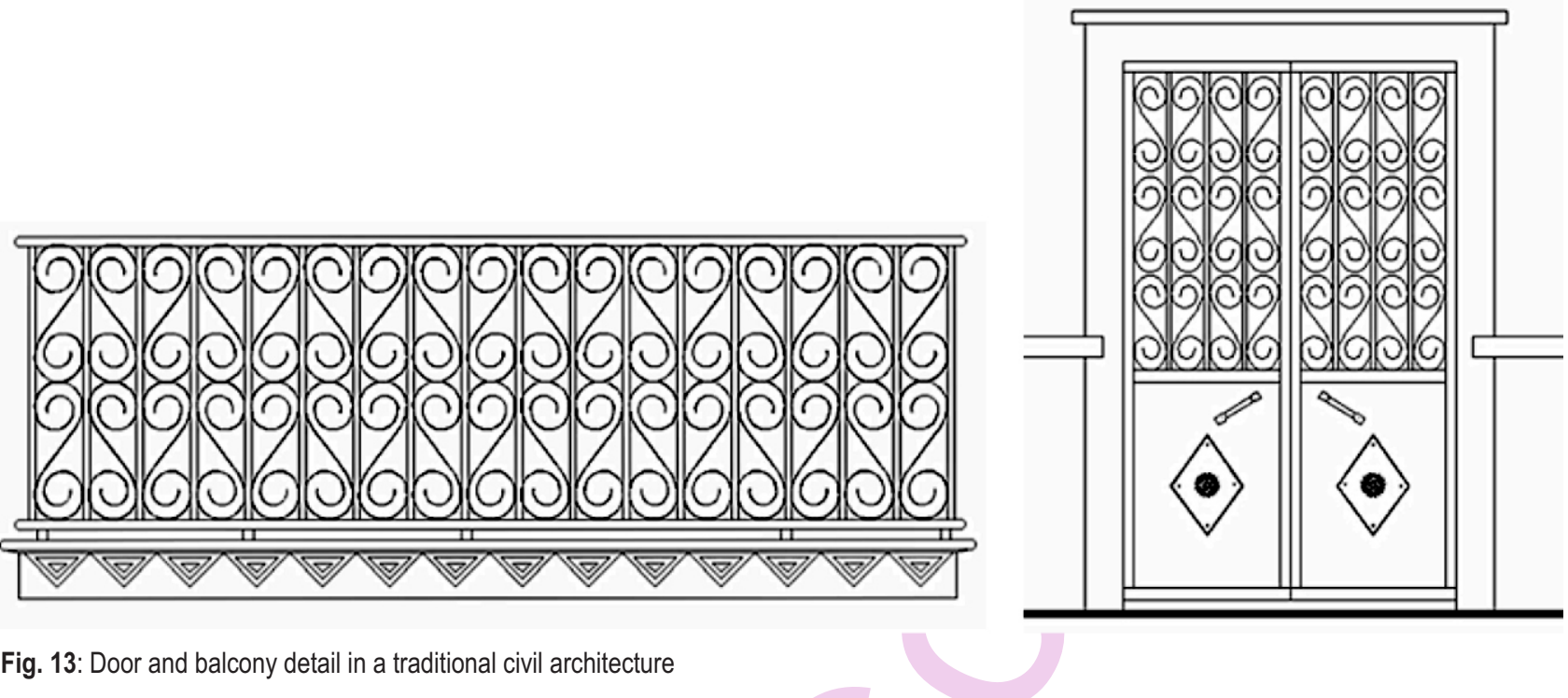

Fig. 13: Door and balcony detail in a traditional civil architecture

The Urban Design Guide in Toronto city enforces Official Plan and urban design objectives via the laws. During the process of approval, these guides helped to turn policy and performance standards into options for the municipality to take them into consideration. But there are Bartın-Urban Protected Area, planning conditions for breakthrough Transition Area Conservation Zoning Plan of the Streets to be protected. It is found that the conditions for breakthrough Transition Area Conservation Zoning Plan of the Streets to be protected are not obeyed, the empty-full ratio of façades in the new buildings are not in harmony with the historical buildings, and that the color, fabric and style of the lighting elements, dustbins, urban community facilities, garden walls and direction plates are not in harmony with each other as well as the historical fabric. It is seen that the maintenance and repair work in the existing plant arrangements in the study area are not sufficient. The reason of this is that Bartın does not have an urban design guide and partial solutions are brought with the plans and projects carried out. As in Toronto, urban design guide in Bartın should be legally enforced. The deficiencies in the process of planning, implementation, management and monitoring processes and the fact that the $40^{\text {th }}$ and $41^{\text {st }}$ articles of the Construction Law (URL6, 2016) cannot be implemented due to political pressures and lack of social awareness, should be removed.

It is necessary to establish Relievo and Renovation Bureau by municipality or governorship, to institutionalize the objective of protecting and improving cultural and historical heritage. Providing the sustainability of historical and cultural identity in urban landscaping through urban design and landscape design projects, functionalizing historical buildings in accordance with public tendencies and ensuring abiding by planning decisions and urban design projects are suggested (Anonymous, 2008). Structural and plantal landscape projects that are in harmony with the building architecture and the period they are constructed should be made during protection and renovation works and the practices should represent the technique of the era they were built. In the zoning process carried out by the municipality, it is suggested that landscape project and practices should be compulsory and that the works are carried out accordingly. Thus, it will be possible to protect the silhouette and visual values in historical cities. Besides, the existing structural and plant condition of the area is identified and the street silhouette of the Kanlırmak Street is prepared (Fig. 9). Figure 10 shows the street silhouette suggested on Kanlırmak Street whilst Figures 11,12 and 13 include the traditional civil architecture example with its details.

Finally, it should be mentioned that urban design guidebooks should be formed in a way that protect natural and cultural heritage as well as traditional architecture, and that they should be formed with the an understanding considering the participation of public.

\section{Acknowledgment}

We would like to express our thanks to Temel Olgun for drawing the street silhouette and traditional civil architecture details' in Kanlırmak Street. We are grateful to personnel of Bartın Municipality, Zoning and Urban Planning Directorate for their help in providing plans and reports about research area.

\section{References}

Anonymous: Bartın Nazım İmar Planı Araştırma Raporu. Bartın Belediyesi, Bartın Belediyesi 01.05.2006 Tarih 86 Sayılı Meclis Kararı, Bartın's Master Plan Research Report. Bartın Municipality, Council Decision No.86 of 01.05.2006 Date Bartın (2006).

Anonymous: Bartın 2023 Stratejik amaçlar ve il gelişme planı. Strategic goals and the city development plan. Bartın Governance Provincial Planning and Coordination Directorate, Bartın (2008). 
Anonymous: Bartın-Kentsel Sit Alanı, Etkileme Geçiş Alanı Korunacak Sokaklar Koruma Amaçıı İmar Planı Plan Koşulları. Bartın-Urban Protected Area, the conditions of the plan were based on breakthrough transition area to be protected Streets Conservation Zoning Plan, Bartın Municipality, Zoning and Urban Planning Directorate, Bartın (2003).

Anonymous: Kültür kenti Bartın'ı keşfedin, Mitolojiden gezginlere. Kültür ve Turizm Envanteri, Discover Bartın culture urban, from mythology to the explorer. Culture and Tourism Inventory, Bartın Provincial Culture and Tourism Directorate Publishing, Ankara (2007).

Aşcıoğlu, E.: Bartın. Bartın Chamber of Commerce and Industry Publication, Ankara (2001).

Çelik, D. and S. Açıksöz: Care of city aesthetics in historical towns: Case of Bartın. J. Bartin Facul. Forestry, 10, 57-65 (2008).

Deng, L.: Construction Quality, Externality, and Community Competitiveness. A Study of Masonry Ordinances in Chicago's Suburbs. Presentation at Annual Meeting of the Association of Collegiate Schools of Planning (ACSP), Kansas City, MO (2005).

Ellis, C.: The New Urbanism: Critiques and Rebuttals. J. Urban Design, 7, 261-291 (2002).

Ely, M. and S. Pitman: Green infrastructure, life support for human habitats, the compelling evidence for incorporating nature into urban environments. Botanic gardens of South Australia, Department of Environment, Water and Natural Resources, (2014)

Erzen, J.: Çevre Etiği. Environmental Ethics. METU Development Foundation Publishing and Communication Co., Ankara (2006).

Erzen, J.: Urban Aesthetics. Turkey Congress of Aesthetics. Architecture J., Issue 334 (2007).

Erzen, J.N.: Çoğul Estetik. Plural Aesthetic. Metis publications, İstanbul (2011).

Galenieks, A.: Importance of urban street tree policies: A Comparison of neighbouring Southern California cities. Urban Urban Gree, 22, 105-110 (2017).

Hong, L. and W. Tao: Urban design practice towards planning management in China-Urban design guidelines in Wuhan City as examples. In: Recent developments in Chinese urban planning (Eds.: Q. Pan and J. Cao). Springer International Publishing, Switzerland, p. 349 (2015).

Keskinok, H.Ç.: Kamusallığın üretimi olarak kentsel estetik. (Ed.: Jale Erzen), Production of the public as the urban aesthetic. In File 23 (Eds.: J. Erzen,), The Chamber of Architects Ankara Branch Publication, Ankara (2010).

Lee, B.K., S.Y. Shon and S. Yang: Design guidelines for the Dashilar, Beijing open green spaces redevelopment project. Urban Urban Gree, 13, 385-396 (2014)

Lynch, K.: Kent imgesi. Image of the city. Turkey Isşbank Cultural Publications, İstanbul (2010).

Madan, S. and P. Verma: Assessment of air pollution tolerance index of some trees in Haridwar City, Uttarakhand. J. Environ. Biol., 36, 645-648 (2015).

Mattila, $\mathrm{H} .:$ Aesthetic justice and urban planning: who ought to have the right to design cities? Geo J., 58, 131-138 (2003).

Özer, M.N. and E. Söylemez: Kent kimliğinin sürekliliği ve değişiminde kentsel tasarım rehberlerinin önemi. The importance of the urban design guidelines in continuity and change in urban identity. Landscape Architecture IV. Congress, 263-272 (2010).

Pollock-Ellwand N.: Cultural landscapes and environmental ethics: The case of Puslinch Township's historic roadside trees. J. Agric. Environ. Ethics, 7, 189-203 (1994).

Roeser, S.: Aesthetics as a risk factor in designing architects. Ethics, design and planning of the built environment. Urban and landscape perspectives (Eds.: C. Basta and S. Moroni), Springer Science-Business Media Dordrecht. 12, 93-105 (2013).

Selitsaniotis, I. and K. Nikolaou: Planning for the upgrading and Increasing of urban green in the city of Larissa, Greece. J. Environ. Prot. Ecol., 10, 394-400 (2009).

Sotoudeh, H. and W.M.Z.M. Abdullah: Evaluation of fitness of desing in urban historical context: From the perpectives of residents. Frontiers of architectural research, 2, 85-93 (2013).

Timuçin, A.: Estetik. Aesthetic. Bulut publications, İstanbul (2008).

Topay, M. and A. Gül: Kentsel Peyzaj Düzenlemelerinin Kentsel İmge ve Kentin Kimlik Kazanmasındaki Rolü. The role of urban landscape design in urban image and urban identity. International Davraz Congress, 680-691 (2009).

URL1: Urban Design Guidelines for Austin. www.austintexas.gov/edims/ document.cfm?id. Accessed: 04.11.2013, (2009).

URL2: Urban Design Guidelines. http://www.city.pittsburgh.pa.us/dt/ UDGuide.pdf. Accessed: 10.10.2013, (1998).

URL3: Nottingham City Center Urban Design Guide. http://www.nottinghamcity.gov.uk/CHttpHandler.ashx?id=7138\& $p=0$. Accessed: $10.10 .2014,(2009)$.

URL4:http://www.toronto.ca/planning/urbdesign/guidelines.htm. Accessed: 22.12.2013, (2013).

URL5: Urban and Landscape Design Guidelines. Downtown Coral Springs. http://coralsprings.org/ home/showdocument?id=3267, Accessed: 26.09.2014, (2002).

URL6: 3194 no Zoning Law http://www.mevzuat.gov.tr/Metin1.Aspx? MevzuatKod=1.5.3194 \&Mevzuatlliski=0\&sourceXmlSearch=\& Tur=1\&Tertip=5\&No=3194, Accessed: 13.07.2016, (2016).

Weina, D., H. Botang, Z. Xin and M. Mazzanti: How does green technology influence $\mathrm{CO}_{2}$ emission in China? - An 2 empirical research based on provincial data of China. J. Environ. Biol., 36, 745-753 (2015).

Zhang, Y. and J. Wang: Optimization of the scheme for natural ecology planning of urban rivers based on ANP (analytic network process) model. J. Environ. Biol., 36, 755-763 (2015).

Ziss, A.: Aesthetic-Reality Artistic Absorb of the Science. İzlenim Art Publisher, İstanbul (2011) 